\title{
Durable behavior facilitating effects of discriminative stimuli*
}

\author{
DONALD D. PATTERSON $\dagger$ \\ and \\ STEPHEN WINOKUR \\ Texas Christian University, Fort Worth, Tex. 76129
}

Pigeons with a past history of keypecking for an auditory conditioned reinforcer (tone) in one component of a multiple schedule, while the conditioned and primary reinforcers were paired in another component, were put on an extinction schedule in which keypecking no longer produced the tone. The keypecking persisted in the absence of the tone but ceased when the discriminative stimulus (red keylight) was replaced with a novel stimulus (yellow keylight).

In a study presented at the Psychonomic Society meeting (1970), Patterson and Winokur reported the autoshaping and maintenance of pigeons' keypecking using only a conditioned reinforcer $\left(\mathrm{S}^{\mathrm{r}}\right)$. We assumed that the conditioned reinforcer was responsible for the conditioning and maintenance of this behavior. An experiment was then designed to determine the extent to which the keypecking was being maintained by the Sr. That experiment, which was reported at the 1971 Southwestern Psychological Association meeting, showed that apparatus cues or conditioned incentive seemed to be contributing to the maintenance of behavior in this situation and led us into the current investigation of the discriminative stimuli used. The present investigation reports the effects of varying discriminative stimuli independently of reinforcement contingencies and shows the effects of these stimuli on behavior.

\section{METHOD \\ Subjects}

Two male Silver King pigeons that had been trained to keypeck for the presentation of a $1000-\mathrm{Hz}$ tone, which previously had been established as a conditioned reinforcer, were used. The birds had approximately 3 months of experience keypecking on a FI 1-min schedule for the tone. Throughout the prior and the present experiment, the birds were maintained at $80 \%$ of their free-feeding weight and received their total daily ration of Purina Pigeon Checkers during the experimental session.

\section{Apparatus}

The birds were run in a BRS-Foringer pigeon chamber. White noise and the noise of a ventilating fan were present at a level of approximately $80 \mathrm{~dB}$. All electromechanical programming and recording equipment was located in an adjacent room.

*This research was supported by a grant from the Texas Christian University Research Foundation and a University Fellowship for Donald D. Patterson.

TReprints may be obtained from Donald Patterson, now at the Department of Psychology, Jacksonville State University, Jacksonville, Alabama $\mathbf{3 6 2 6 5}$.

\section{Procedure}

The birds received daily 150 -min sessions during which a random sequence of $10-\mathrm{min}$ components of a three-component multiple schedule was presented. In the response component of this schedule, the key was transilluminated with a red light and keypecking on a FI 1-min schedule produced $5 \mathrm{sec}$ of $1000-\mathrm{Hz}$ tone at $80 \mathrm{~dB}$ (white noise off during the tone presentation). In the extinction component, the key was green. Responses were recorded but had no programmed consequences. In the pairing component, birds received response-independent pairings of the $1000-\mathrm{Hz}$ tone and the full food magazine. These pairings occurred on the average of once a minute, programmed by a VI 1-min timer (VT $1 \mathrm{~min}$ ). The key was not illuminated and responses, except those during the tone, had no programmed consequences. Responses during the tone shut off the tone and prevented the next schedule's magazine presentation (DRO $5 \mathrm{sec}$ ).

In the main portion of the present experiment, the procedure was identical to that described above, except that keypecks in the presence of the response component's red keylight no longer produced the $S^{r}(1000-\mathrm{Hz}$ tone). This made the contingencies in the response and extinction components the same, with the pairing component unchanged throughout the experiment. This schedule remained in effect for 29 daily sessions.

Following this, the response component's red keylight was replaced with a novel yellow light for 5 days. Responding was still not reinforced in this component. The response component's keylight was then returned to its original red for 7 days, followed by 5 more days of yellow and 6 days of red.

In the final portion of the experiment, the keylight in the response component was red and keypecks were reinforced on a FI 1-min schedule with the 5-sec tone presentation.

\section{RESULTS}

Each bird's average rate of responding during the last 5 days of the response-contingent tone procedure (baseline) is indicated by a horizontal bar in Fig. 1. During the first 29 days of extinction in the presence of the red keylight, there was a slight decrease in response rates during the response component. Figure 1 shows daily response rates for both of the birds. Despite the absence of primary or secondary reinforcement in the response component, both birds continued to peck at rates in excess of one response per minute for a considerable period of time. Furthermore, there was no indication of any tendency for responding to decrease, as is usually observed in experimental extinction. Table 1 shows that the mean rate of responding during the last 5 days of the extinction procedure was lower than baseline for Bird 18 but higher than baseline for Bird 20.

This finding prompted the hypothesis that the red keylight was maintaining the behavior. Changing the keylight to yellow brought about a drop in response rates, to 0 for Bird 18 and to less than 0.18 for Bird 20 . Returning the light to the original red color brought about an immediate increase in response rates, although 
Table 1

Average Response Rates in Responses Per Minute for Birds 18 and 20 During Successive Phases of the Experiment

\begin{tabular}{lccccccc}
\hline & \multirow{2}{*}{$\begin{array}{c}\text { Last 5 Days } \\
\text { of Baseline }\end{array}$} & $\begin{array}{c}\text { Last 5 Days } \\
\text { of Extinction }\end{array}$ & Yellow SD & Red SD & Yellow SD & Red S & Baseline \\
\cline { 5 - 8 } & 3.22 & 1.07 & 0.00 & 0.38 & 0.00 & 0.67 & 4.53 \\
Bird 18 & 1.09 & 1.43 & 0.18 & 0.45 & 0.04 & 0.45 & 2.40 \\
Bird 20 & & &
\end{tabular}
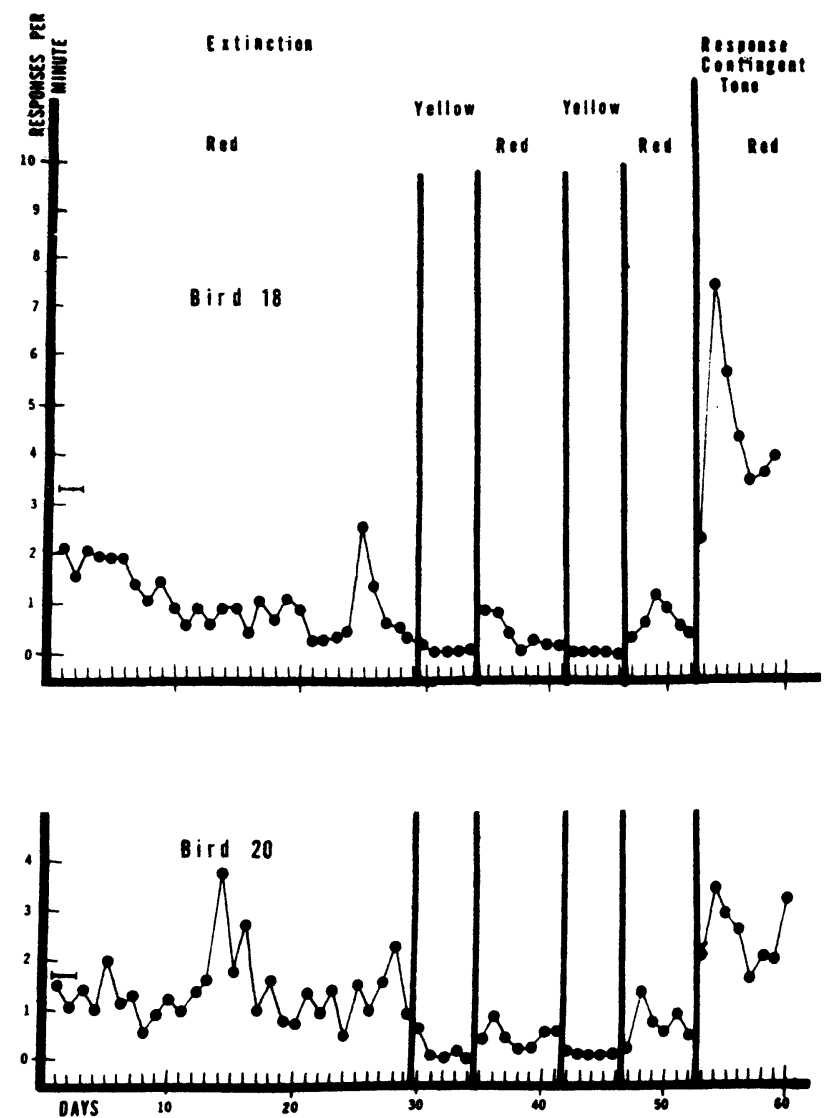

Fig. 1. Daily response rates of Birds 18 and 20 showing the effects of extinction and the change in $S^{D}$ color. (The first horizontal bars show the mean rate of responding for the last 5 days of baseline.)

they were somewhat lower than prior to the use of the yellow light (see Table 1). The return to yellow again produced an immediate cessation of responding by Bird 18 and a very low rate of pecking by Bird 20. The reinstatement of the red keylight again resulted in an increase in rate of responding to approximately that level displayed during the previous red light. A sign test was used to compare the response rates of each bird in the presence of the red and yellow lights. Each 5-day period of yellow was compared with the succeeding 5-day period of red to yield an $\mathrm{N}$ of 10 per bird. Responding in the presence of red was significantly higher than during the yellow for both birds (Bird 18: $\mathrm{p}<.01$; Bird 20: $\mathrm{p}<.05$ ).

As can be seen from Fig. 1 and Table 1, the return of the response-contingent tone presentations resulted in an increase in responding for both of the birds.

\section{DISCUSSION}

No experiments other than the present one have demonstrated the maintenance of behavior solely with a $S^{D}$. This failure can perhaps be attributed to the fact that, in most situations, the $S^{r}$ and $S^{D}$ coexist as one stimulus that is paired with the presentation of a primary reinforcer $\left(S^{R}\right)$.

The present investigation differs from other experiments in that the $S^{r}$ and $S^{D}$ are separate stimuli, each presented to a different sensory modality. Also, the birds in this experiment have no past history of keypecking for $\mathbf{S}^{\mathbf{R}}$; they were autoshaped using a $S^{\mathbf{r}}$ and keypecks contiguous with primary reinforcement were prevented by using a DRO $5 \mathrm{sec}$ during the tone-food pairing. The power of the $S^{D}$ to control behavior may possibly be related to the fact that the Ss never responded for a $S^{R}$ or simply that the $S^{D}$ was presented to the pigeons' dominant sensory modality of vision.

These data show that the controlling stimulus does not have to be response contingent in order to be effective. That is, control of response rate or probability by discriminative stimuli may be of sufficient strength to maintain behavior, despite the prolonged absence of response-contingent reinforcers. Perhaps this may help explain the persistence of human behavior, such as reading, without "slow and careful shaping of verbal behavior through differential reinforcement [Chomsky, 1959]." Durable stimulus control may be an automatic product of weak conditioned reinforcers, while slow and careful shaping may be of no consequence.

\section{REFERENCES}

Chomsky, N. Review of Skinner's Verbal Behavior. Language, 1959, 35, 26-58.

Patterson, D. D., \& Winokur, S. Autoshaping pigeons' keypecking with a conditioned reinforcer. Paper presented at the meeting of the Psychonomic Society, San Antonio, November 1970.

Patterson, D. D., \& Winokur, S. Generalized excitatory effects of a response-independent reinforcer presentation. Paper presented at the meeting of the Southwestern Psychological Association, San Antonio, April 1971.

(Received for publication January 11, 1973.) 